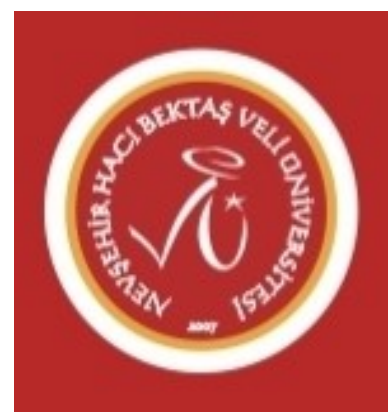

Nevşehir Bilim ve Teknoloji Dergisi

Araştırma Makelesi (Research Article)

Makale Doi: 10.17100/nevbiltek.644118

Geliş Tarihi: 07-11-2019

Kabul Tarihi 19-02-2020

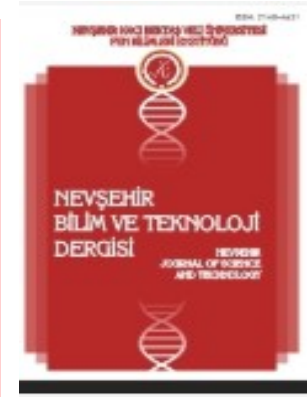

\title{
Östemperlenmiş Küresel Grafitli Dökme Demirlerde XRD Yöntemiyle Yüksek Karbonlu Östenit Faz Hacim Oranını Belirlemede Yüzey Koşullarının Etkisi
}

\author{
Burak NALÇACI ${ }^{1}$, Volkan KILIÇLI ${ }^{2}$, Mehmet ERDOĞAN ${ }^{3}$ \\ ${ }^{1}$ Gazi Üniversitesi, Teknoloji Fakültesi, Metalurji ve Malzeme Mühendisliği Bölümü, 06500, Ankara \\ ORCID ID: 0000-0002-3919-7061 \\ ${ }^{2}$ Gazi Üniversitesi, Teknoloji Fakültesi, Metalurji ve Malzeme Mühendisliği Bölümü, 06500, Ankara \\ ORCID ID: 0000-0002-0456-5987 \\ 3 Gazi Üniversitesi, Teknoloji Fakültesi, Metalurji ve Malzeme Mühendisliği Bölümü, 06500, Ankara \\ ORCID ID: 0000-0003-4430-9360
}

$\ddot{\mathbf{O z}}$

Bu çalışmada XRD (X-Işınları kırınımı) yöntemiyle yüksek karbonlu östenit faz hacim oranı belirlenmesinde yüzey koşullarının yüksek karbonlu östenit faz hacim oranı üzerine etkisi araştırılmıştır. Böylelikle XRD analizinde uygun yüzey koşulunun belirlenmesi hedeflenmiştir. Bu amaç doğrultusunda, alaşımlı küresel grafitli dökme demire $900^{\circ} \mathrm{C}$ 'de 2 saat östenitleme ve $375^{\circ} \mathrm{C}$ 'deki tuz banyosunda 2 saat östemperleme ve ardından oda sıcaklığına havada soğutma işlemi uygulanmıştır.

Isıl işlem sonrası dört eşit parçaya ayrılarak farklı yüzey koşullarında hazırlanan numuneler optik ve SEM (Taramalı Elektron Mikroskobu) ile incelenmiş, XRD analizleri yapılmış ve makro sertlik ölçümleri gerçekleştirilmiştir.

XRD yöntemiyle yüksek karbonlu östenit faz hacim oranı ölçümlerinde farklı yüzey koşullarının östenit faz hacim oranı ölçümü üzerinde oldukça etkili olduğu gözlemlenmiştir. XRD yöntemiyle faz hacim oranı belirlenmesinde polisaj+dağlama işleminin yüzey pürüzlülüğünü azalttı̆̆ı için oldukça etkili olduğu tespit edilmiştir.

Anahtar Kelimeler: Östemperlenmiş Küresel Grafitli Dökme Demir (ÖKGDD), Yüksek Karbonlu Östenit Faz Hacim Oranı, Yüzey Pürüzlülüğü, XRD (X-Işınları Kırınımı).

\section{The Effect of Surface Conditions in Determination of High Carbon Austenite Phase Volume Fraction by XRD Method in Austempered Ductile Iron}

Abstract

In this study, the effect of surface preparation conditions on high carbon austenite phase volume fraction measurement in determination of high carbon austenite phase volume fraction by XRD (X-Ray Diffraction) method was investigated. Thus, it was aimed to determine the appropriate surface condition in XRD analysis. For this purpose, alloyed ductile iron was subjected to austenitization at $900^{\circ} \mathrm{C}$ for 2 hours, austempering at $375^{\circ} \mathrm{C}$ for 2 hours and then air cooling to room temperature.

After heat treatment, the samples were divided into four equal parts and examined samples having different surface conditions by optical and SEM (Scanning Electron Microscope), XRD analysis and macro hardness measurements were performed.

It was observed that different surface conditions were highly effective on austenite phase volume fraction measurement in high carbon austenite phase volume fraction measurements by XRD method. It was determined that polishing+etching process is very effective in detecting the phase volume fraction by XRD method because it reduces surface roughness.

Keywords: Austempered Ductile Iron (ADI), High Carbon Austenite Phase Volume Fraction, Surface Roughness, XRD.

1. Giriş

Dökme demir türleri içerisinde küresel grafitli dökme demirler (KGDD) en iyi süneklik ve dayanım kombinasyonunu sağlamaktadırlar [1]. Bu avantajları ve üretim maliyetlerinin düşük olması nedeniyle imalat 
Nevşehir Bilim ve Teknoloji Dergisi (2020), 9(1) 52-62

endüstrisinde pek çok parça üretiminde yaygın bir şekilde kullanılmaktadır [2-5]. Küresel grafitli dökme demirlerin östemperlenmesi sonrası yüksek mukavemet, süneklik, aşınma direnci ve geliştirilmiş yorulma dayanımları çeliklerle kıyaslanabilecek özellikler sağlamaktadır [6-9]. Çelikler ve dökme demir malzemelerde mikro yapıyı oluşturan fazların hacim oranları malzemenin mekanik özelliklerini belirlemede büyük önem taşımaktadır [6,10]. Özellikle bu durum, yapısında östenit içeren düşük alaşımlı yüksek mukavemetli çelikler [11], çift fazlı çelikler [12], TRIP çelikleri [13] ve östemperlenmiş küresel grafitli dökme demirler (ÖKGDD) [14] gibi malzemeler için büyük önem taşımaktadır.

KGDD'lerin östemperlenmesi sonucu ilk aşamada mikro yapı beynitik ferrit $\left(\alpha_{b}\right)$ ve yüksek karbonlu östenitten $\left(\gamma_{\mathrm{ykö}}\right)$ oluşmaktadır [15] .

$\gamma \rightarrow \alpha_{b}+\gamma_{\text {ykö }}$

Östemperlenme 1 sıl işlemi ikinci aşamasında yüksek karbonlu östenit, $\left(\gamma_{\mathrm{ykkö}}\right)$ karbür ve ferrite $(\alpha)$ dekompoze olmaktadır [15] .

$\gamma_{\mathrm{ykkö}} \longrightarrow \alpha+$ Karbür

Mikro yapıdaki yüksek karbonlu östenitin hacim oranı mekanik özellikleri büyük ölçüde etkilemektedir. Bu nedenle yüksek karbonlu östenitin faz hacim oranı yapı-özellik ilişkisi açısından oldukça büyük önem arz etmektedir [16,17]. Daha önce yapılan bazı çalışmalarda araştırmacılar [13,18-21,22] ÖKGDD’lerde yüksek karbonlu östenitin mekanik olarak kararlı olmadığını belirtirken diğer araştırmacılar [23,24] tam tersi şekilde görüşs sunmuşlardır. Yüksek karbonlu östenitin kararlılığı içerdiği karbon miktarına, morfolojisine ve çevreleyen fazlara bağlıdır [17, 25].

Mikro yapıdaki faz hacim oranı mekanik özellikleri ciddi bir şekilde etkilediği için doğru karakterize edilmesi yapılan çalışma için büyük önem taşımaktadır. XRD analiz yöntemi bu amaçla en sık kullanılan yöntemlerden bir tanesidir. XRD analiz yöntemleri sayesinde faz analizleri, kalıntı gerilim analizleri ve tekstür analizleri gerçekleştirilebilmektedir [26,27]. Üretilen X-ışınlarının numune yüzeyinden saçınımının dedektör vasıtasıyla tespit edilmesi prensibine dayanan XRD yöntemi çeşitli ölçüm koşullarından etkilenmektedir. Ayrıca karakterizasyon için yüzey hazırlama işlemlerinin faz dönüşümüne etki edebildiği bilinmektedir [28-30,32].

$\mathrm{Bu}$ sebeple XRD analizlerinden önce farklı karakterizasyon yöntemleriyle bu durumun kontrol edilmesinin daha nitelikli XRD analizine katkı sağlayacağı düşünülmektedir. Gerçekleştirdiğimiz çalışmada bu durum sertlik testiyle faz dönüşümü arasındaki korelasyon incelerek sağlanmıştır. XRD analizi öncesi metalografi işlemleri sırasında oluşabilecek faz dönüşümleri incelemesi sağlandıktan sonra bulk malzemelerde yüzey pürüzlülük derecesinin etkisini net bir şekilde ortaya koymak amacıyla, bu çalışmada alaşımlı östemperlenmiş küresel grafit dökme demirde yüksek karbonlu östenitin faz hacim oranının XRD yöntemiyle belirlenmesinde yüzey hazırlığının yüksek karbonlu östenit faz hacim oranı üzerine etkisi araştırılmıştır. Literatüre bulk malzemelerde yüzey koşullarının ne ölçüde XRD analizini etkilediğine dair bu çalışmanın kazandırılmasının yapılan çalışmaların doğru yorumlanmasına destek olacağı düşünülmektedir.

\section{Materyal ve Metot}

Deneysel çalışmalarda Tablo 1'de kimyasal kompozisyonu verilen alaşımlı küresel grafitli dökme demir kullanılmıştır. Dökümler ISO 1083'e uygun Y-II tipi kum kalıplara dökülerek elde edilmiştir. Deneysel çalışmalarda Y bloğun alt bölgesinden kesilen 20x20x10 mm boyutlarındaki numuneler kullanılmıştır.

\begin{tabular}{ccccccccccccccc}
\multicolumn{10}{c}{ Tablo 1. Deneysel çalışmalarda kullanılan alaşımlı küresel grafitli dökme demirin kimyasal kompozisyonu (\% ağırlık) } \\
\hline $\mathbf{C}$ & $\mathbf{S i}$ & $\mathbf{M n}$ & $\mathbf{P}$ & $\mathbf{S}$ & $\mathbf{M g}$ & $\mathbf{C r}$ & $\mathbf{N i}$ & $\mathbf{M o}$ & $\mathbf{C u}$ & $\mathbf{A l}$ & $\mathbf{T i}$ & $\mathbf{F e}$ \\
3,52 & 3,195 & 0,403 & 0,02 & 0,014 & 0,042 & 0,032 & 1,341 & 0,222 & 0,6065 & 0,19 & 0,011 & Kalan \\
& & & & & & & & & & & & & &
\end{tabular}

Dökülmüş koşullarda mikroyapı ferrit+perlit+grafitten oluşmuştur (Şekil 1). 
Nevşehir Bilim ve Teknoloji Dergisi (2020), 9(1) 52-62

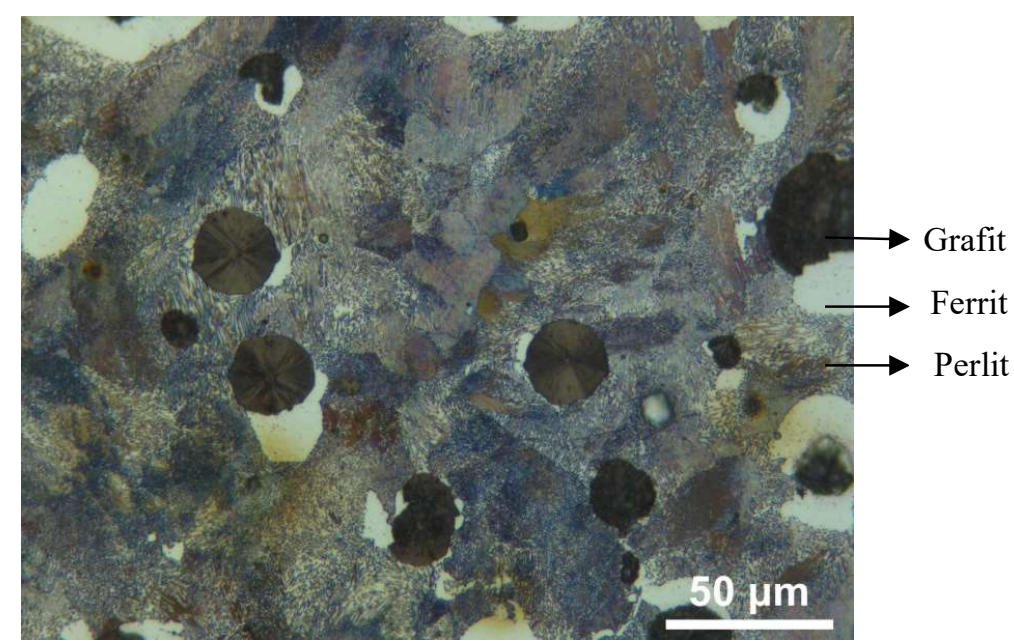

Şekil 1. Dökülmüş koşullardaki mikroyapı (Dağlama \%2 nital)

Östemperleme işlemi Heraeus marka elektrik direnci ile çalışan en fazla $1150^{\circ} \mathrm{C}^{\prime}$ ye kadar tavlamanın yapılabildiği atmosfer kontrolü olmayan bir firında KGDD numune firın sıcaklığ $1900^{\circ} \mathrm{C}$ 'de iken firına sevk edilmiş 2 saat östenitlemenin ardından $375^{\circ} \mathrm{C}$ 'de tuz banyosunda 2 saat izotermal beklemeden sonra oda sicaklığına havada soğutma suretiyle gerçekleştirilmiştir. Uygulanan 1sıl işlemlerin özeti Şekil 2'de verilmiştir.

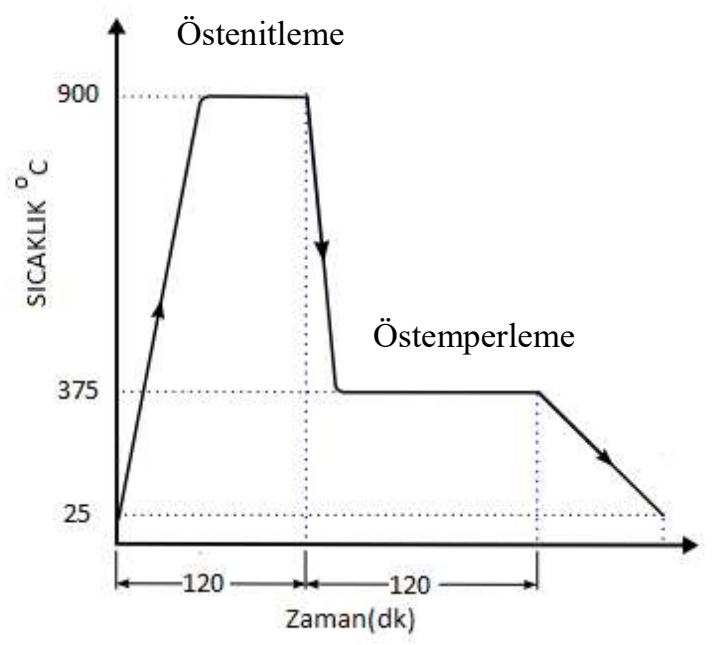

Şekil 2. Uygulanan 1 ș1 işlemlerin özeti

Bu koşullarda 2 saat östemperleme sonucunda mikroyapıyı östemperlenmiş küresel grafitli dökme demirlerde gözlenen en iyi mekanik özellikleri sağlayan tipik beynitik ferrit, yüksek karbonlu östenit ve grafitin oluşturduğu gözlemlenmiştir (Şekil 3) 


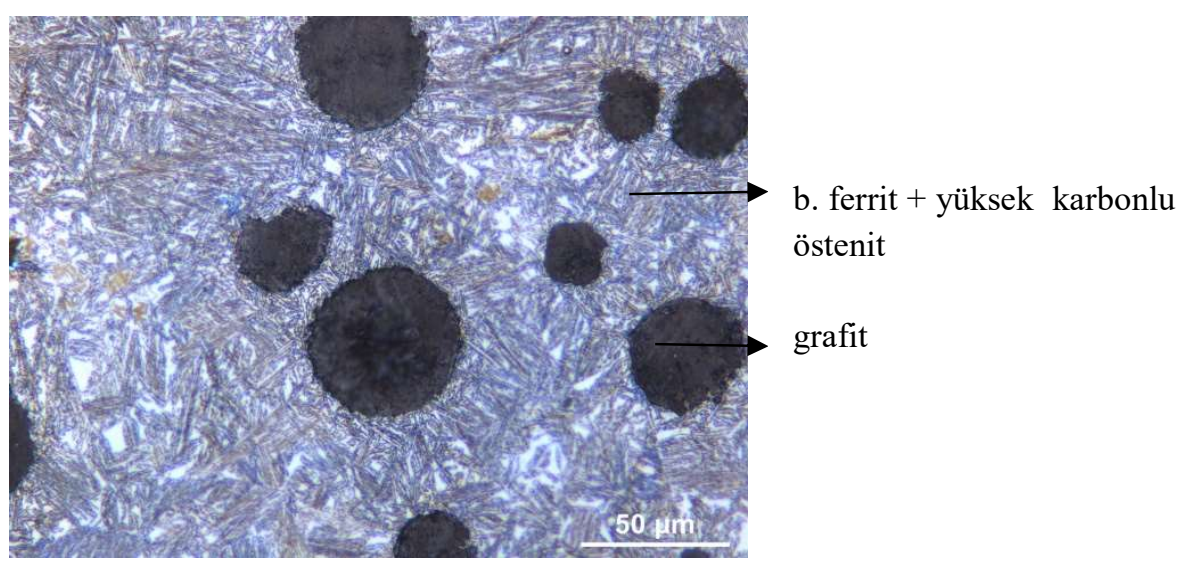

Şekil 3. $900^{\circ} \mathrm{C}^{\prime}$ de 2 saat östenitlenmiş ardından 375 C'de 2 saat östemperlenmiş ve oda sıcaklığına havada soğutulmuş küresel grafitli dökme demir mikro yapısı. Mikro yapı beynitik ferrit+yüksek karbonlu östenit+grafitten oluşmuştur. (Dağlama \%2 nital)

Isıl işlem esnasında yüzeyde oluşabilecek dekarbürize tabaka yüzeyden şerit testere vasıtasıyla kaldırılmıştır. XRD yöntemiyle yüksek karbonlu östenit faz hacim oranı ölçümünde yüzey hazırlık koşullarının etkisini görmek amacıyla dört farklı yüzey koşulu elde edilmeye çalışılmıştır. Bu amaçla dört farklı koşula sahip yüzeyler, farklı grid numarılarına sahip zımparalama, zımparalama+polisaj ve zımparalama+polisaj+dağlama yöntemleriyle hazırlanmıştır. Dağlayıcı olarak \%2 nital çözeltisi kullanılmıştır [31].

Yüzey pürüzlülüğü ölçümleri Mitutoyo-Surftest-301 taşınabilir yüzey pürüzlülük ölçüm cihazı ile yapılmıştır. Her numune üzerinden beş farklı bölgeden ölçüm yapılmış ve ölçümlerin aritmetik ortalaması alınmıştır. Numunelere uygulanan yüzey hazırlık işlemlerinin özeti, numune adları ve yüzey pürüzlülük ölçüm sonuçları Tablo 2’de verilmiştir.

Tablo 2. Numune adları, uygulanan yüzey hazırlık işlemleri ve yüzey pürüzlülük ölçüm değerleri

\begin{tabular}{|c|c|c|}
\hline Numune Adl & Uygulanan Yüzey Hazırlığı İşlemi & $\begin{array}{c}\text { Yüzey pürüzlülüğ̈̈ } \\
(\mathrm{Ra}, \mu \mathrm{m})\end{array}$ \\
\hline \#120 & Zimpara (120\#) & $0,52 \pm 0,06$ \\
\hline$\# 1200$ & Zimpara $(120 \# \rightarrow 320 \# \rightarrow 600 \# \rightarrow 800 \# \rightarrow 1200 \#)$ & $0,36 \pm 0,04$ \\
\hline Polisaj & Zımpara $(120 \# \rightarrow 320 \# \rightarrow 600 \# \rightarrow 800 \# \rightarrow 1200 \#) \rightarrow$ Polisaj $(6 \mu \mathrm{m} \rightarrow 3 \mu \mathrm{m} \rightarrow 1 \mu \mathrm{m})$ & $0,13 \pm 0,02$ \\
\hline Dağlanmış & $\begin{array}{l}\text { Zımpara }(120 \# \rightarrow 320 \# \rightarrow 600 \# \rightarrow 800 \# \rightarrow 1200 \#) \rightarrow \text { Polisaj }(6 \mu \mathrm{m} \rightarrow 3 \mu \mathrm{m} \rightarrow 1 \mu \mathrm{m}) \rightarrow \% 2 \\
\text { nital çözeltisiyle } 10 \mathrm{sn} \text { dağlama }\end{array}$ & $0,11 \pm 0,01$ \\
\hline
\end{tabular}

Dört farklı yüzey koşuluna sahip numunelerin yüzeyleri Leica DFC 320 dijital kamera bağlantılı Leica DM 4000M marka optik mikroskobunda ve JEOL JSM-6060LV marka elektron mikroskobunda incelenmiştir. Yüksek karbonlu östenit faz hacim oranı1 Bruker D8 Advance XRD cihazı kullanılarak elde edilen XRD deseni üzerinden ile hesaplanmıştır. X-ışını kaynağı olarak monokromatik CuK $\alpha$ ışını $\left(\lambda=1.54056 \mathrm{~A}^{\circ}\right)$ kullanılarak $40 \mathrm{kV}$ ve $40 \mathrm{~mA}$ 'da XRD desenleri elde edilmiştir. Numuneler $2 \theta 40-100^{\circ}$ aralığında 0,02 tarama hızında taranmıştır. Yüksek karbonlu östenit faz hacim oranının belirlenmesinde (200), (220) östenit ve (200), (211) ferrit piklerinin tümleşik alanları kullanılmıştır. Kalıntı östenit hesaplamalarda ASTM E975'te belirtilen denklem 1 kullanılmıştır [32] .

$$
\mathrm{V} \gamma=\frac{0.5\left[\frac{I_{\gamma(200)}}{R_{\gamma(200)}}+\frac{I_{\gamma(220)}}{R_{\gamma(220)}}\right]}{0.5\left[\frac{I_{\alpha(200)}}{R_{\alpha(200)}}+\frac{I_{\alpha(211)}}{R_{\alpha(211)}}\right]+0.5\left[\frac{I_{\gamma(200)}}{R_{\gamma(200)}}+\frac{I_{\gamma(220)}}{R_{\gamma(22)}}\right]}
$$

Burada I; ilgili pikin altında kalan alanı ve R her pik için ayrı hesaplanan bir değerdir. Bu formülüzasyon vasıtasıyla Şekil 6 ve 7'deki veriler formülde belirtildiği gibi pikin altında kalan alan ve $2 \theta$ açısına bağlı olarak hesaplanmıştır.

Yüzey hazırlık koşullarının numunelerin mikro yapısında muhtemelen oluşturabileceği değişikliğin sertlik değerlerine yansımasını görmek amacıyla numunelerin sertlik değerleri ölçülmüştür. 


\section{Nevşehir Bilim ve Teknoloji Dergisi (2020), 9(1) 52-62}

Sertlik değerleri Emcotest Duravision 200 model üniversal sertlik cihazı kullanılarak Vickers sertlik ölçme yöntemiyle ( $136^{\circ}$ elmas piramit uç, 30kgf yükte $10 \mathrm{sn}$ bekleme) belirlenmiştir. Numunelerin sertlik değerleri, aynı numune üzerinde en az 5 farklı bölgeden alınan sertlik değerlerinin ortalaması olarak belirlenmiştir.

\section{Bulgular ve Tartışma}

Numunelerin optik mikroskop ve tarama elektron mikroskoplarıyla elde edilmiş yüzey görüntüleri sırasıyla Şekil 4 ve Şekil 5 'te verilmiştir.
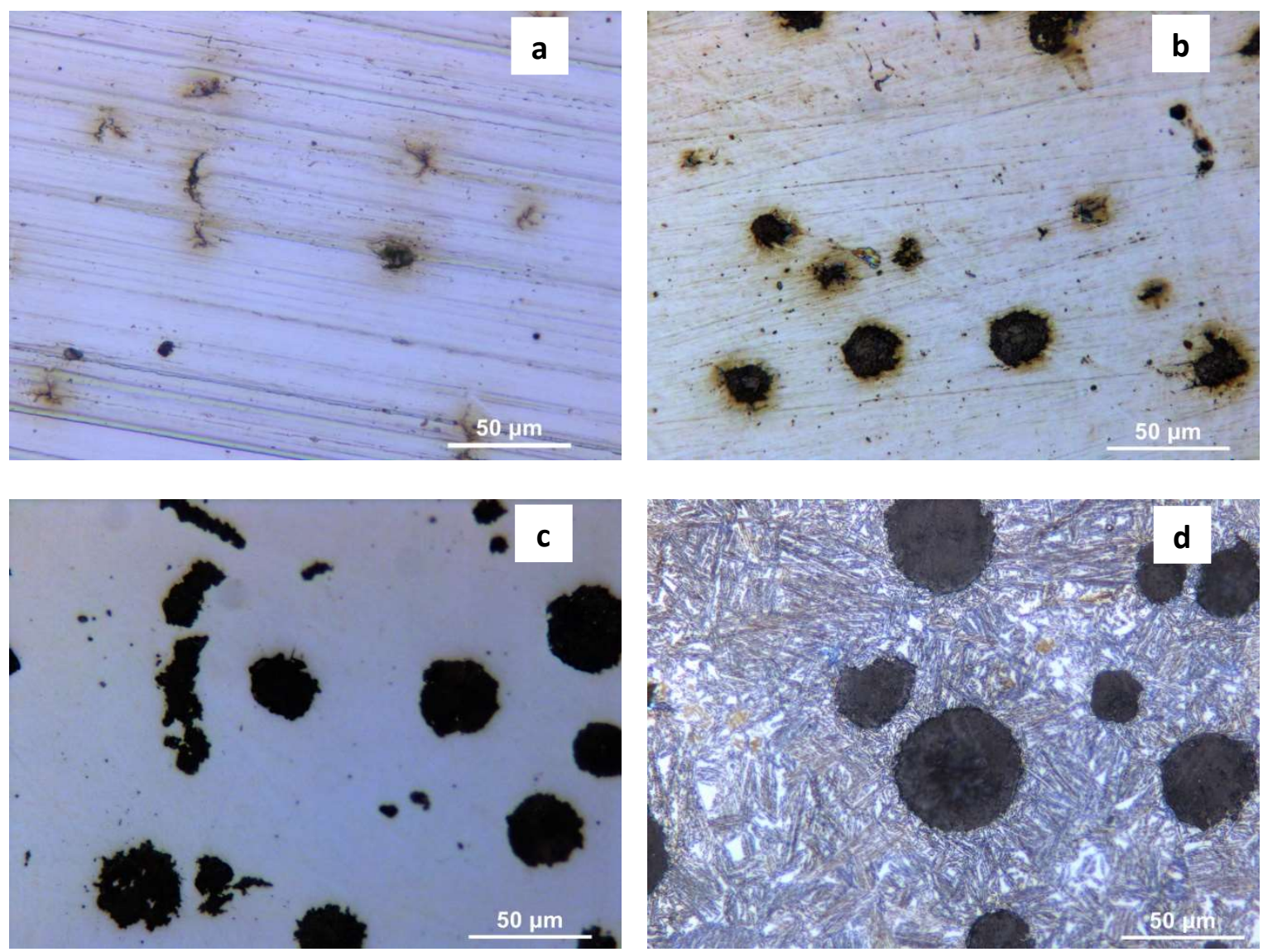

Şekil 4. ÖKGDD'in farklı yüzey koşullarında optik mikroskopta elde edilmiş mikroyapı görüntüleri; a) 120 grit b) 1200 grit c) Polisaj d) dağlanmış (\%2 nital) (Büyütme: X200)

Optik mikroskop görüntüleri incelendiğinde beklenildiği gibi en kaba yüzey 120\#'lik zımpara ile hazırlanan numunede gözlemlenirken (Şekil 4a ve Şekil 5a), 1200\#‘lik zımpara ile hazırlanan yüzeyde kılcal çizikler görülmektedir (Şekil 4b ve Şekil 5b). Yüzeyi polisaj yapılmış numunede herhangi bir çizik gözlemlenmemiştir (Şekil 4c ve Şekil 5c). \%2 nital ile dağlanan numunede tipik ösferritik yapı $\left(\alpha_{b}+\gamma_{y k k o ̈)}\right)$ ortaya çıkmıştır (Şekil $4 d$ ve Şekil $5 d$ ).
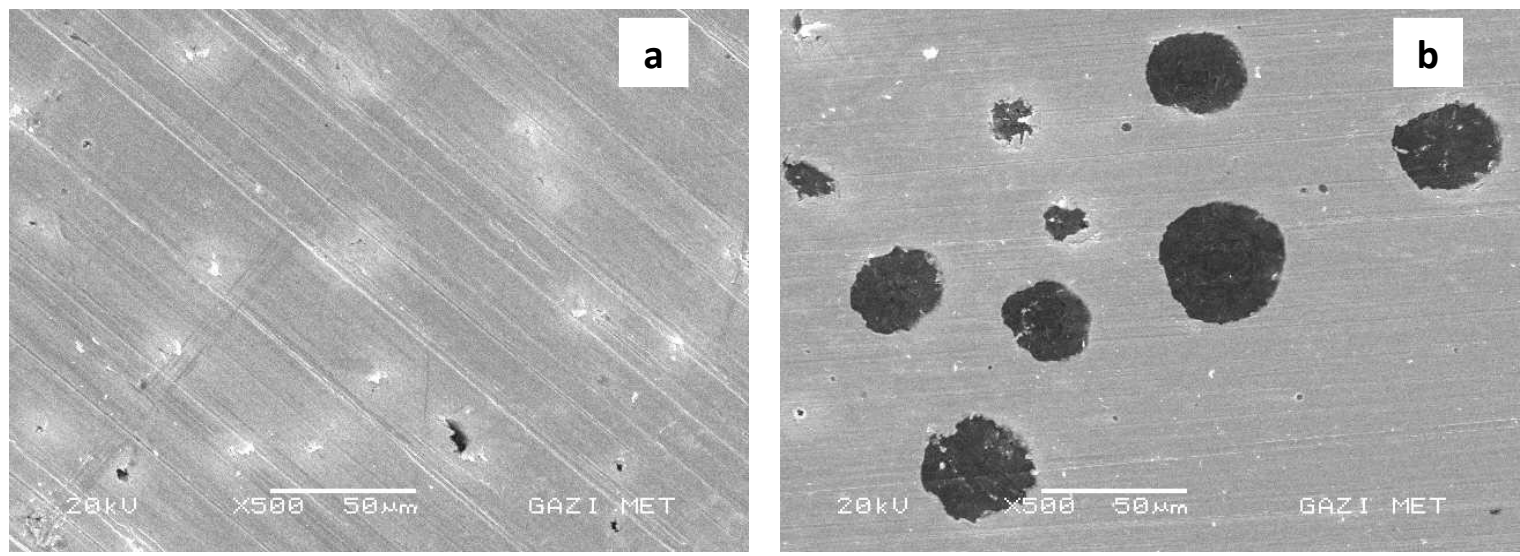
Nevşehir Bilim ve Teknoloji Dergisi (2020), 9(1) 52-62
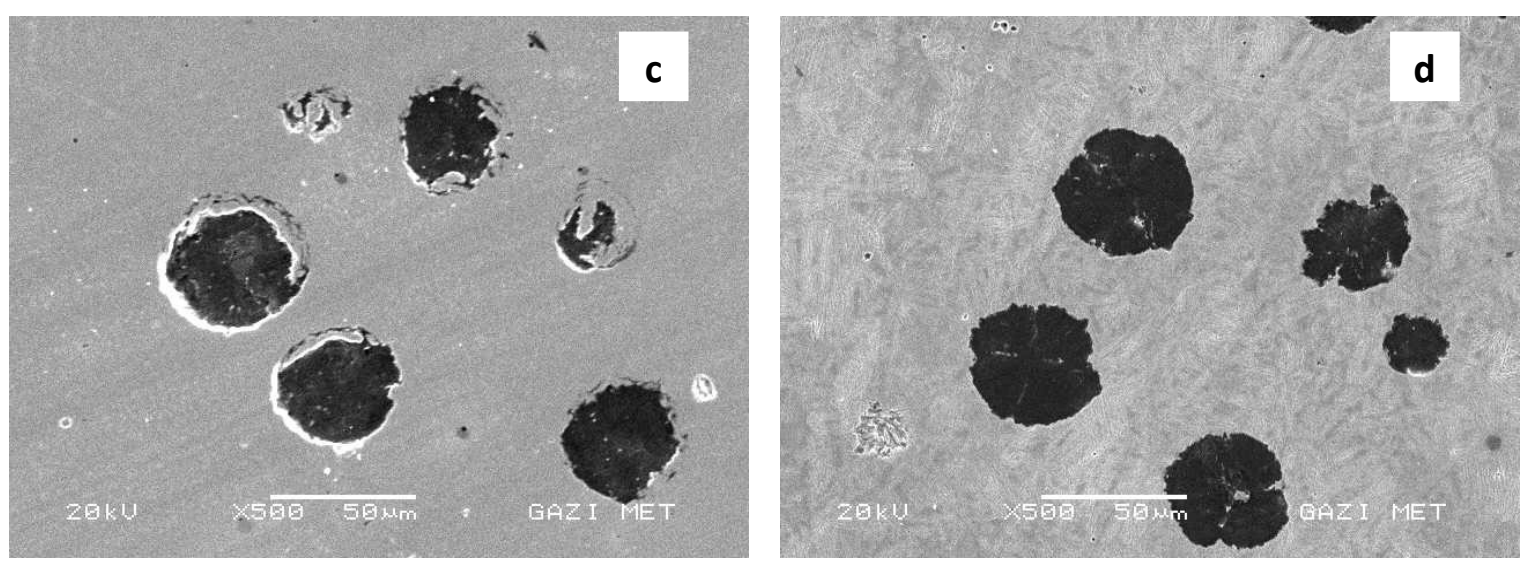

Şekil 5. ÖKGDD'in farklı yüzey koşullarında SEM'de elde edilmiş mikrografileri; a)120 grit b)1200 grit c) polisaj d) dağlanmış

Dört farklı yüzey koşuluna sahip numunelerin XRD desenleri Şekil 6'da ve yüzey pürüzlülüğü-yüksek karbonlu östenit faz hacim oranları arasındaki ilişki Şekil 7'de verilmiştir.

Yüzey koşullarının, XRD desenleri etkilediği (Şekil 6) numunelerin yüksek karbonlu östenit faz hacim oranlarında önemli farkl11ıklar oluşturduğu (Şekil 7) görülmektedir.

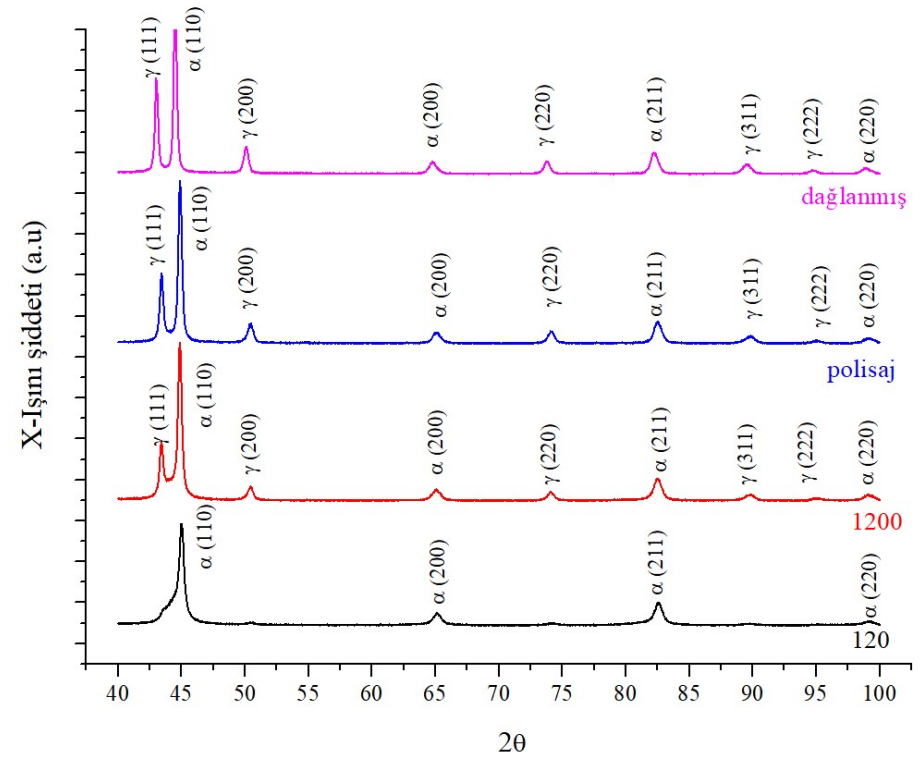

Şekil 6. Dört farklı yüzey koşuluna sahip numunelerin XRD desenleri

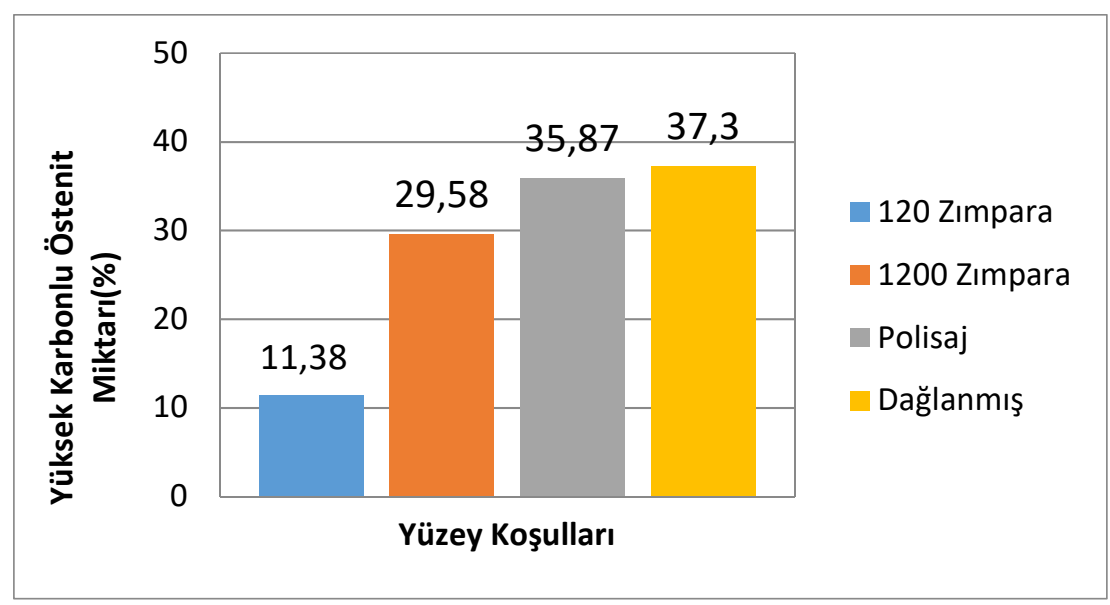


Şekil 7. Dört farklı yüzey koşuluna sahip numunelerde östenit faz hacim oranı

Şekil 7'de dört farklı yüzey koşuluna sahip numunelerde yüzey pürüzlülüğü-yüksek karbonlu östenit faz hacim oranları arasındaki ilişki gösterilmektedir.

Kaynak ve arkadaşları [33] tarafından yapılan çalışmada talaşlı imalat ile gerçekleştirilen bitirme işleminin yüzey pürüzlülüğünü azalttığı ve bu durumun XRD desenlerini oldukça etkilediği ifade edilmiştir. Pitschke ve arkadaşları yaptıkları çalışmada yüksek yüzey pürüzlülüğüne sahip numunelerde X-Işını mikro absorbsiyonun X-Işıııı şiddetini azalttığını ifade etmişlerdir [34].

Zhang ve arkadaşları [16] yüksek karbonlu östenit faz hacim oranının belirlenmesi üzerine yaptıkları çalışmada XRD ile yapılan analizlerde numunenin yüzeyinin tam olarak düz olmamasının X-Işını şiddetinde varyasyonlara sebep olduğunu ifade etmişlerdir. Suortti [35] yaptığı floresans ölçümü çalışmasında X-Işını şiddetindeki azalmanın numunedeki porozite ve pürüzlülükten kaynaklandığını belirtmişlerdir. Şekil 6, 7 ve Tablo 2 incelendiğinde yukarıdaki literatür çalışmalarıyla benzer şekilde yüzey pürüzlülüğünün X-1şını şiddetinde mikro absorpsiyonlara sebebiyet verdiği aynı zamanda numuneden X-ışını refleksiyonlarında çeşitli varyasyonlara sebebiyet vererek farklı XRD desenleri ortaya çıkardığı değerlendirilmektedir.

Dağlama işlemi uygulanan numunenin polisaj işlemi uygulanan numuneye göre yüzey pürüzlülüğünde nispi azalma gözlenmiştir (Tablo 2).

Ayrıca dağlayıcının yüzey pürüzlülüğü üzerine etkisini mikro ve makro düzeyde görmek amacıyla 1200 \# zımpara+dağlanmış ve 1200 \# zımpara (dağlanmamış) işlemi uygulanarak iki numune daha hazırlanmıştır. Numunelerin optik mikroskop ve stereo makroskopla görüntüleri alınmıştır. Bu görüntülerden anlaşılacağı üzere dağlama uygulanan numunede yüzey pürüzlülüğ ü azalmıştır.

Bu sonuç Tablo 2'de verilen dağlanmış (polisaj+dağlanmış) ve polisaj (dağlanmamış) numunelerdeki yüzey pürüzlülüğü ölçümleri arasındaki farkı açıklamaktadır. Bu durum literatürdeki diğer çalışmalarla benzerlik göstermektedir [36-38]. Yüzey pürüzlülüğündeki azalma dağlayıcının türü ve uygulanma süresiyle ilgilidir.

Bu çalışmada dağlama işlemi 10 sn süreyle \%2 Nital çözeltisi kullanılarak gerçekleştirilmiştir. Şekil 8a ve 9a'da rahatlıkla gözlenen çizikler şekil $8 b$ ve $9 b$ 'de güçlükle görülebilmektedir.
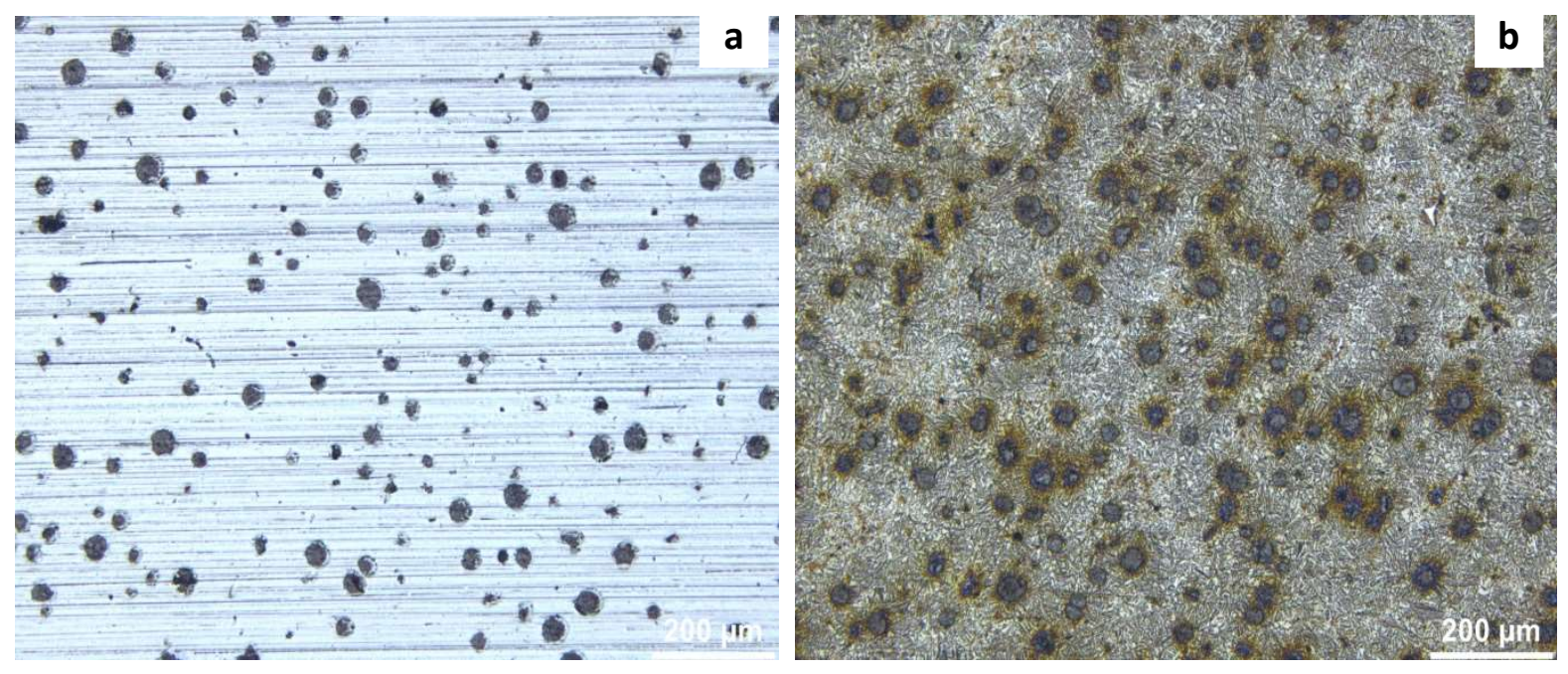

Şekil 8. 1200\# zımpara ile hazırlanmış numunelerin optik mikroskopla elde edilmiş görüntüleri a)1200 grit, b)1200 grit+dağlama 

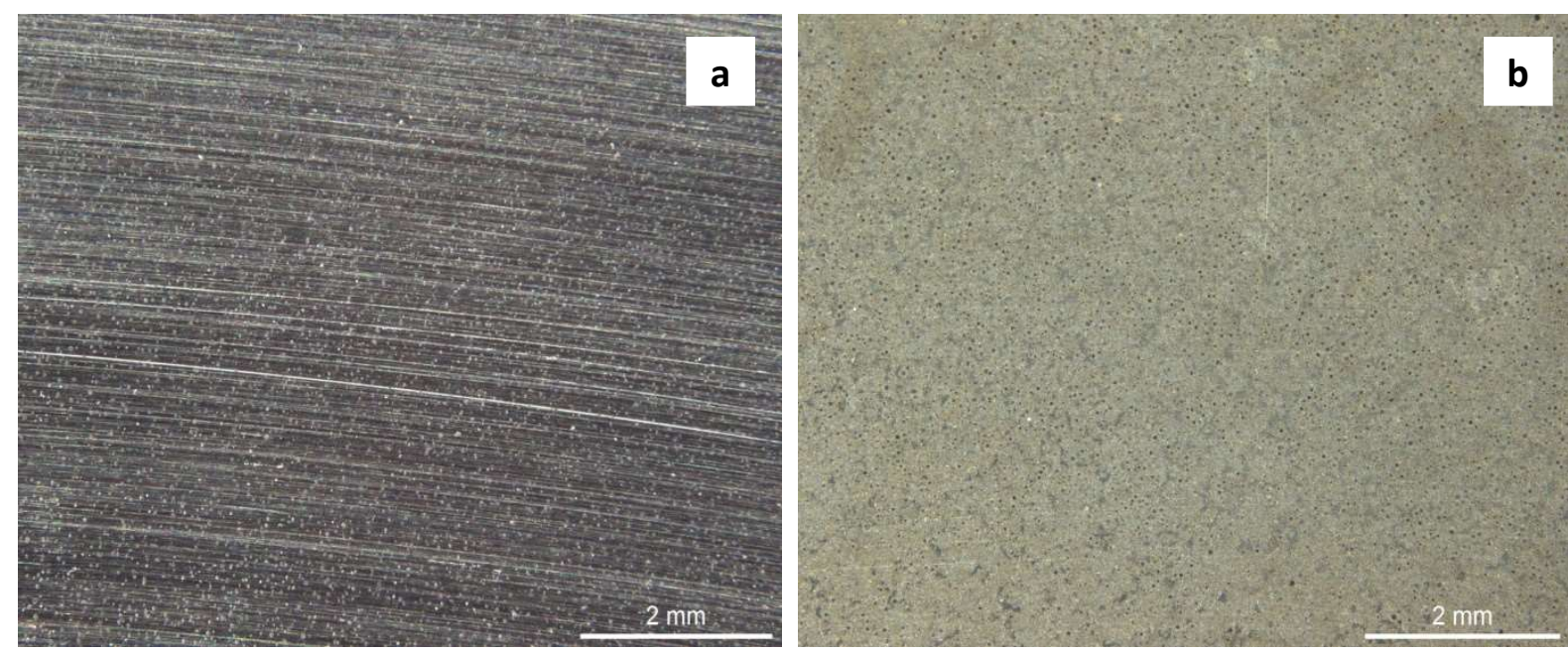

Şekil 9. 1200\# zımpara ile hazırlanmış numunelerin stereo mikroskopla elde edilmiş makrografileri a)1200 grit, b)1200 grit+dağlama

Dört farklı yüzey koşuluna sahip numunelerin sertlik ölçüm sonuçları Tablo 3’te verilmiştir.

Tablo 3. Sertlik Sonuçları

\begin{tabular}{cc}
\hline Numune & Sertlik (HV30) \\
\hline 120 Zımpara & $324 \pm 6$ \\
1200 Zımpara & $318 \pm 5$ \\
Polisaj & $304 \pm 10$ \\
Dağlanmış & $315 \pm 4$ \\
\hline
\end{tabular}

Tablo 3'teki sertlik sonuçları incelendiğinde numunelerin sertlik değerleri arasında ciddi fark gözlemlenmemiştir. $\mathrm{Bu}$ sonuç dört farklı yüzey koşulu oluşturma işlemlerinin ÖKGDD numunelerin mikro yapısında önemli bir değişim oluşturmadığının bir göstergesi olarak düşünülebilir. Mikro yapıda ciddi bir değişiklik olmamasına rağmen XRD analizinde yüksek karbonlu östenit faz hacim oranının farklı olmasının nedeninin yüzey pürüzlülüğü olduğu netleşmiştir.

\section{Sonuc}

$\mathrm{Bu}$ çalı̧̧mada östemperlenmiş küresel grafitli dökme demirde yüksek karbonlu östenit faz hacim oranının XRD yöntemiyle belirlenmesinde numunenin yüzey hazırlığı ve yüzey koşullarının etkisi araştıılmış, aşağıdaki sonuçlar elde edilmiştir.

1- Östemperlenmiş küresel grafitli dökme demirlerde XRD ile yüksek karbonlu östenit faz hacim oranını belirlemede, yüzey pürüzlülüğü yüksek karbonlu östenit faz hacim oranını önemli ölçüde etkilemektedir.

2- Yüksek karbonlu östenit faz hacim oranlarındaki farklıllğın sebebi olarak, pürüzlülüğe bağlı X-1şını mikroapsorbsiyonları ve reflekte olan ışınların düzensiz dağılımından kaynaklanan hatalar olduğu düşünülmektedir.

3- XRD yöntemiyle faz hacim oranı belirlemede polisaj+dağlama işleminin yüzey pürüzlülüğünü azaltmada oldukça etkili olduğu gözlemlenmiştir.

4- Sertlik sonuçları incelendiğinde numunelerin sertlik değerleri arasında ciddi fark gözlemlenmemiştir. Bu durum ÖKGDD'de yüzey hazırlama işlemleri sırasında ciddi bir faz dönüşümü olmadığını işaret etmektedir. 
Nevşehir Bilim ve Teknoloji Dergisi (2020), 9(1) 52-62

5- Kullanılan dağlayıcı ve uygulama süresinin malzemeye göre farklılıklar gösterdiği bilinmektedir. ÖKGDD’lerde \%2 Nital dağlayıcının 10 sn numune üzerine uygulanmasının yüzey pürüzlülüğünü azalttığı gözlemlenmiştir. Bu durumun nedeni olarak pürüzlü alanlarda yüzey alanı daha fazla olduğu için dağlayıcının bu bölgelere daha fazla etki ederek yüzey pürüzlülüğünü azalttığı, ÖKGDD’lerde dağlayıcının birim zamanda etkisinin araştırmaya açık olduğu düşünülmektedir.

\section{Teşekkür}

XRD çalışmalarında yardımını esirgemeyen Dr. Meryem Polat Gönüllü’ye ve çalışmamızın gerçekleştirilmesinde kullanmış olduğumuz alt yapı ve laboratuvar imkânlarının kurulmasını sağlayan Gazi Üniversitesi Bilimsel Araştırma Projeleri birimine teşekkür ederiz.

\section{Kaynaklar}

[1] Sabarudin S., Pratikto P., Suprapto A., Irawan Y. S., "Effect of heat treatment and cryogenics on hardness of ductile cast iron microstructure (FCD-50)" Eastern-European Journal of Enterprise Technologies, 2, 20-26, 2018.

[2] Boccardo A.D., Dardati P.M., Godoy L.A., Celentano D.J., "Sensitivity of Austempering Heat Treatment of Ductile Irons to Changes in Process Parameters" Metallurgical and Materials Transactions B, 49, 1522-1536, 2018.

[3] Colombo D.A., Dommarco R.C., Basso A.D., "Rolling contact fatigue behavior of dual-phase austempered ductile iron" Wear, 418-419, 208-214, 2019.

[4] Samaddar S., Das T., Chowdhury A. K., Singh M., "Manufacturing of Engineering components with Austempered Ductile Iron - A Review” Materials Today Proceedings., 5, 25615-25624, 2018.

[5] Wang C., Liu R., Li S., Gu C., Du X., Sun Y., Tian J., "Effect of austempering temperature on microstructure of ausferrite in austempered ductile iron” Materials Science and Technology, 35, 1329-1336, 2019.

[6] Witte M., Lesch C., "On the improvement of measurement accuracy of retained austenite in steel with X-ray diffraction” Materials Characterization, 139, 111-115, 2018.

[7] Ovali I., Kilicli V., Erdogan M., "Effect of microstructure on fatigue strength of intercritically austenitized and austempered ductile irons with dual matrix structures" ISIJ International, 53, 375-381, 2013.

[8] Taşdelen M.E., Yeşilyurt H., "AISI 4140 Çeliğinin Çeşitli Çift Fazlı Mikroyapılarında Mekanik Özellikleri İle Sürtünme Davranışı İlişkisinin İncelenmesi” Nevşehir Bilim ve Teknoloji Dergisi, 4, 88-96, 2015.

[9] Kilicli V., Erdogan M., “Tensile Properties of Partially Austenitized and Austempered Ductile Irons with Dual Matrix Structures” Materials Science and Technology, 22, 919-928, 2006.

[10] Mark A.F., Wang X., Essadiqi E., Embury J., Boyd D., "Development and characterisation of model TRIP steel microstructures" Materials Science and Engineering A, 576, 108-117, 2013.

[11] Lai J., Huang H., , Buising W., "Effects of microstructure and surface roughness on the fatigue strength of highstrength steels" Procedia Structure Integrity, 2, 1213-1220, 2016.

[12] Dutta T., Das D., Banerjee S., Saha S. K., , Datta S., "An automated morphological classification of ferritemartensite dual-phase microstructures" Measurement, 137, 595-603, 2019.

[13] Azizi G., Mirzadeh H., , Parsa M. H., "The effect of primary thermo-mechanical treatment on TRIP steel microstructure and mechanical properties” Materials Science and Engineering A, 639, 402-406, 2015.

[14] Dakre V., Peshwe D.R., Pathak S.U., Likhite A., "Effect of austenitization temperature on microstructure and 
Nevşehir Bilim ve Teknoloji Dergisi (2020), 9(1) 52-62

mechanical properties of low-carbon-equivalent carbidic austempered ductile iron" International Journal of Minerals, Metallurgy, and Materials, 25, 770-778, 2018.

[15] Panneerselvam S., Martis C. J., Putatunda S. K., , Boileau J. M., "An investigation on the stability of austenite in Austempered Ductile Cast Iron (ADI)” Materials Science and Engineering A, 626, 237-246, 2015.

[16] Zhang M. X., Kelly P. M., Bekessy L. K., Gates J. D., "Determination of retained austenite using an X-ray texture goniometer" Materials Characterization, 45, 39-49, 2000.

[17] Chang L. C., "Carbon content of austenite in austempered ductile iron" Scripta Materialia., 39, 35-38, 1998.

[18] Boschen R., Bomas H., Mayr P .,Vetters H., "Strength and fatigue of Austempered Ductile Iron(ADI)" World Conference on Austempered Ductile Iron, Des Plaines, IL, USA, 468s, 1991.

[19] Vuorinen J. J, "Strain-hardening mechanism and characteristics of austempered ductile iron" AFS Trans. 86, 577-588, 1983.

[20] Mayr P., Vetters H., Walla J., "Investigations on the stress induced martensite formation in Austempered Ductlile Cast Iron(ADI) "2nd International Conference on Austempered Ductile Iron, Ann Arbor, MI, USA, 171s, 1986.

[21] Hayrynen K. L., Moore D. J., Rundman K. B., "Tensile properties and microstrusture of a clean austempered ductile iron" AFS Trans. 98, 471-480, 1990.

[22] Fu Y. T., Liu J., Shi J., Cao W. Q., Dong H., "Effects of Cold Rolling Reduction on Retained Austenite Fraction and Mechanical Properties of High-Si TRIP Steel” Journal of Iron Steel Research International, 20, 50-56, 2013.

[23] Sidjanin L., Smallman R. E., Boutorabi S. M., “ Metallography of bainitic transformation in austempered ductile iron” Materials Science and Technology, 8, 1095-1103, 1992.

[24] Sidjanin L., Smallman R. E., Boutorabi S. M., "Microstructure and fracture of aluminum austempered ductile iron investigated using electronmicroscopy” Materials Science and Technology, 10, 711-723, 1994.

[25] Varshney A., Sangal S., Kundu S., Mondal K., "Super strong and highly ductile low alloy multiphase steels consisting of bainite, ferrite and retained austenite" Materials \&Design, 95, 75-88, 2016.

[26] Cullity, B.D. "Elements of X-ray diffraction”, Addison-Wesley Publishing, 313s, USA, 1956.

[27] Epp, J. "X-ray diffraction (XRD) techniques for materials characterization.Materials characterization using Nondestructive Evaluation (NDE) methods" Woodhead Publishing, 81s, UK, 2016.

[28] Molkeri A., Pahlevani F., Emmanuelawati I., Sahajwalla V., "Thermal and mechanical stability of retained austenite in high carbon steel: An in-situ investigation,” Materials Letters, 163, 209-213, 2016.

[29] ASTM E975-13, "Standard Practice for X-Ray Determination of Retained Austenite in Steel with Near Random Crystallographic Orientation" ASTM, 1-7, 2013.

[30] Qiao X., Han L., Zhang W., Gu J., "Nano-indentation investigation on the mechanical stability of individual austenite in high-carbon steel" Materials Characterization, 110, 86-93, 2015.

[31] ASTM E407-07, "Standard Practice for Microetching Metals and Alloys" ASTM, 1-14, 2015.

[32] Roberts C.S. "Effect of carbon on the volume fractions and lattice parameters of retained austenite and martensite" Transactions of AIME 197, 203-204, 1953.

[33] Kaynak Y., Tascioglu E., "Finish machining-induced surface roughness, microhardness and XRD analysis of selective laser melted Inconel 718 alloy" Procedia CIRP, 71, 500-504, 2018.

[34] Pitschke, W., Hermann, H., \& Mattern, N. The influence of surface roughness on diffracted X-ray intensities in Bragg-Brentano geometry and its effect on the structure determination by means of Rietveld analysis" Powder Diffraction, 8, 74-83, 1993.

[35] Suortti, P., "Effects of porosity and surface roughness on the X-ray intensity reflected from a powder specimen" 
Nevşehir Bilim ve Teknoloji Dergisi (2020), 9(1) 52-62

Journal od Applied Crystallography, 5, 325-331, 1972.

[36] Sun Y. Y., Gulizia S., Oh C. H., Fraser D., Leary M., Yang Y. F., Qian M.., “The Influence of As-Built Surface Conditions on Mechanical Properties of Ti-6Al-4V Additively Manufactured by Selective Electron Beam Melting” JOM, 68, 791-798, 2016.

[37] Kim B., Lee B.T., Han J.G., "Surface roughness of silicon oxynitride etching in C2F6 inductively coupled plasma," Solid State Electronics, 51, 366-370, 2007.

[38] Zhu C., Jiao Q., Tan X., Hu H., Bayanheshig, "The effects of TMDD-PA concentration on roughness of $\mathrm{Si}<110>$ and etching rate ratio of $\mathrm{Si}<110>/<111>$ in alkaline KOH solution” Chemical Physics, 529, 110397, 2019. 